\title{
Can Type 2 Diabetes Mellitus and its Chronic Complications Influence the Level of Maximal Oxygen Uptake of Exercise Participants?
}

Valesca Nayara Silva ${ }^{1 *}$, William Valadares Campos Pereira ${ }^{1,2^{*}}$, Anthony Rodrigues Vasconcelos ${ }^{1}$, Maria Elizabeth Queiroz Holanda do Nascimento $^{1}$, Riara Bezerra Pontes de Medeiros ${ }^{1}$, Samantta de Araújo Pereira ${ }^{1}$, Jonathan Nícolas dos Santos Ribeiro ${ }^{1}$ and Denise Maria Martins Vancea ${ }^{1,3}$

${ }^{1}$ Physical Exercise and Chronic Non-Transmissible Diseases Research Group, University of Pernambuco, Recife, Brazil.

${ }^{2}$ Federal University of Minas Gerais-UFMG, Belo Horizonte, Brazil.

${ }^{3}$ Permanent Professor of the Postgraduate Program in Physical Education at the Federal University of Pernambuco.

*Corresponding Author: William Valadares Campos Pereira, PhD in Biological Sciences: Physiology and Pharmacology from Federal University of Minas Gerais, Av. Pres. Antônio Carlos, Pampulha, Belo Horizonte, Brazil.

\section{Received Date: 24 August 2021 | Accepted Date: 10 September 2021 | Published Date: 16 September 2021}

Citation: Valesca N Silva, W V C Pereira, Anthony R Vasconcelos, M E Q H Nascimento, R B P Medeiros, et al. (2021). Can Type 2 Diabetes Mellitus and its Chronic Complications Influence the Level of Maximal Oxygen Uptake of Exercise Participants?. Endocrinology and Disorders. 5(5): DOI: $10.31579 / 2640-1045 / 088$

Copyright: (c) 2021 William Valadares Campos Pereira, This is an open-access article distributed under the terms of the Creative Commons Attribution License, which permits unrestricted use, distribution, and reproduction in any medium, provided the original author and source are credited.

\begin{abstract}
:
Patients with type 2 diabetes have reduced aerobic capacity, negatively reflecting on their daily life and prompt independence. Greater damage can be harmed by the presence of chronic complications from diabetes, but this can be mitigated by the effects of physical exercise. The aim of the study was to assess the level of maximum oxygen consumption of people with type 2 diabetes who already have chronic complications and exercise practitioners and also compare with the reference value for women of age group, exercisers and without diagnosis of diabetes. The study was characterized as descriptive, a sample composed of 10 women with type 2 diabetes, mean age of $53 \pm 13$ years, as who had chronic complications from diabetes such as autonomic and peripheral neuropathy, retinopathy and hypertension and who participated in Doce Vida - Supervised Physical Exercise Program for Diabetics / ESEF / UPE. The group participated in a training protocol combined with 20 minutes of walking and 04 strength exercises (protocol $\mathrm{A}$ and $\mathrm{B}$ ) in each physical exercise session. The weekly frequency of training was three times a week, in the morning period. To assess VO2max, the Rockport 1-Mile Walking Test was performed, the volunteers were instructed to walk as fast as possible. For data analysis, the t-test was applied to a sample, with a significance level of $\mathrm{p} \leq 0.05$. The results obtained showed an average of $16.8 \mathrm{ml} / \mathrm{kg} / \mathrm{min}$ of VO2max in the volunteers, values lower than the ideal average for the age ( $53 \pm 13$ years) of women without diabetes, which corresponds to $28.2 \mathrm{ml} / \mathrm{kg} / \mathrm{min}(\mathrm{p}=0.02)$. Therefore, it is concluded that women with type 2 diabetes with the presence of chronic complications, similar levels of VO2max complications are lower than recommended for the same age group of women without diabetes. Therefore, it is suggested that women with the profile of the participants in this study should undergo a cautious progression of physical exercise, better adaptation and adherence to physical exercise.
\end{abstract}

Keywords (Mesh): diabetes mellitus; oxygen consumption; exercise; physical exertion; exercise test

\section{Introduction}

Physical exercise has been recommended as a non-pharmacological treatment, as it acts in the prevention and control of several diseases. An example of the recommendation of physical exercise can be observed in the treatment of obesity, to prevent inflammatory effects mediated by changes in the expression of cytokines, genes and proteins that influence the metabolism and the functioning of several systems, which may lead to the development of diseases such as diabetes mellitus (DM) [1].

Brazil ranks 4th among the 10 countries with the highest number of cases with DM, with an epidemic characteristic, reaching 12.5 million cases, which may double in the next 10 to 25 years [2]. According to the American Diabetes Association (2020) [3], type 2 diabetes mellitus 
(DM2) accounts for $90 \%$ to $95 \%$ of diabetes cases, affecting mostly obese individuals.

The treatment of DM2 is multidisciplinary and is based on diet, medication and exercise, in addition to psychosocial support that includes diabetes education ${ }^{4}$. If diabetics do not adhere to treatment and maintain blood glucose levels above the recommended levels, there is a greater likelihood of chronic complications arising from diabetes, such as retinopathy, nephropathy, neuropathy and cardiovascular disease, which are responsible for the largest number of deaths in diabetics $[5,6]$.

People with diabetes are three times more likely to die than the general population, much of it due to the increased risk of cardiovascular disease [7]. A low level of physical fitness is associated with an increased risk of premature death from a variety of causes, primarily cardiovascular disease [8]. It has been shown that individuals with type 1 diabetes have some components related to impaired physical fitness, in addition to changes in cardiorespiratory responses to exercise, such as decreased lung ventilation associated with decreased maximal $\mathrm{O} 2$ consumption and exercise capacity [9].

Therefore, physical exercise (PE) becomes a fundamental tool in the treatment of diabetes and can be performed through different types and methods $[5,10]$. Aerobic training has been shown to be effective in controlling metabolic, blood pressure, physical fitness and improving anthropometrics in individuals with diabetes $[11,12]$.

The benefits of a systematized practice of PE are related to improved glucose uptake by the skeletal muscle cell, through increased translocation of GLUT-4 to the cell membrane (Lyra, Santos, Cavalcanti, 2019), promoting decreased insulin resistance, increased muscle strength and endurance, flexibility and anthropometric measures, as well as reducing the risk of developing cardiovascular disease and improving cardiorespiratory fitness $[13,14]$.

With advancing age, the individual undergoes changes in muscles, which can reflect in loss of muscle mass, sarcopenia and loss of cardiovascular fitness $[15,16]$. It is believed that strength exercise, aerobic exercise, balance and nutritional support can minimize the loss of function and the impact on the individual's daily activity and may be an effective strategy in the prevention and treatment of this process $[16,17]$.

It is currently believed that combined training, that is, the combination of two types of exercise (aerobic and strength) in the same training session, may promote greater benefits for metabolic control of DM2, in addition to cardiovascular and respiratory improvement and reduction of cholesterol levels $[18,16,19]$.
Cardiorespiratory capacity is measured through the amount of oxygen that the individual can use during PE (VO2max) (Pollock \& Wilmore, 1993). This capacity is related to the individual's ability to live with greater independence, since it is considered one of the main components of physical fitness related to health [20,21].

In aerobic exercise training prescriptions, cardiopulmonary exercise tests, are considered the gold standard to assess cardiorespiratory fitness, to determine the levels of maximal oxygen consumption at distinct intensities of aerobic exercise training and to evaluate cardiovascular and respiratory responses [22].

The American Heart Association classification, established in 1972, is often used to compare levels of cardiorespiratory fitness. It is not known how extrapolable these data may be for other populations, as different nationalities may have distinct population profiles [23]. Brazil does not yet have solid data for this classification.

The presence of Type 2 Diabetes diagnosis and consequent chronic complications from sustained hyperglycemia reduce physical activity and quality of life of this public, becoming a global health challenge, however, few studies have compared the VO2max of this public, with reference tables, after the intervention of a combined exercise protocol.

Therefore, the objective of this study was to evaluate the level of maximal oxygen consumption of people with type 2 diabetes, with chronic complications and practicing physical exercise and compare it with the reference value for women of the same age group, practicing exercise and without diabetes diagnosis.

\section{Methods}

This study is characterized as descriptive. It is part of a larger project entitled "Effects of Aerobic, Resistance and Combined Training on Glycemic Control and Body Composition of Type 2 Diabetics", approved by the Ethics and Research Committee of the University of Pernambuco (CEP/UPE: 007/09). It is associated with the Research Group Physical Exercise and Non-Transmissible Chronic Diseases registered in the $\mathrm{CNPq}$ Research Directory.

General descriptive aspects of the participants are presented in table 1. Ten women with type 2 Diabetes Mellitus (DM2), from Doce Vida Supervised Physical Exercise Program for Diabetics from Escola Superior de Educação Física da Universidade de Pernambuco ESEF/UPE, with a mean age of $53 \pm 13$ years ( $\mathrm{SD} \pm 8.87$ years) of $\mathrm{DM} 2$ diagnosis. All of them were diagnosed with autonomic and peripheral neuropathy, retinopathy and hypertension. Only $20 \%$ of the participants reported using insulin as part of their treatment.

\begin{tabular}{|l|l|l|l|l|l|}
\hline Variables & $\mathbf{n}$ & Mean & Minimum & Maximum & Standard Deviation \\
\hline Age & 10 & 53 & 47 & 75 & 8,07 \\
\hline Time of Diabetes & 10 & 14,7 & 3 & 32 & 8,87 \\
\hline Insulinized* & 10 & 02 & $\mathrm{X}$ & $\mathrm{X}$ & $\mathrm{X}$ \\
\hline Hypertension & 10 & 10 & $\mathrm{X}$ & $\mathrm{X}$ & $\mathrm{X}$ \\
\hline AutonomicNeuropathy & 10 & 10 & $\mathrm{X}$ & $\mathrm{X}$ & $\mathrm{X}$ \\
\hline Peripheral Neuropathy & 10 & 10 & $\mathrm{X}$ & $\mathrm{X}$ & $\mathrm{X}$ \\
\hline Retinopathy & 10 & 10 & $\mathrm{X}$ & $\mathrm{X}$ & $\mathrm{X}$ \\
\hline
\end{tabular}

Legend: $n$ : number of participants. Mean \pm SD: Mean and standard deviation in years. Time of Diabetes: Time of DM2 diagnosis. *Insulinized: Participants who use insulin as part of their treatment. X: Not applicable. 
The inclusion criteria were having been diagnosed with type 2 diabetes and having been diagnosed with at least one chronic complication resulting from diabetes. The exclusion criteria were having some osteomyoarticular problem that prevented the practice of PE, hypoglycemia at the time of collection, report of nocturnal hypoglycemia the night before collection, hyperglycemia over $250 \mathrm{mg} / \mathrm{dL}$ at the time of collection.

\section{Combined Training Protocol}

The participants performed the previously scheduled combined training protocol three times a week on alternate days. The sessions were held from 7 am to 9 am, after the routine meal, at the Sports Gym and the Biodynamics Laboratory of the School of Physical Education ESEF/UPE, under the supervision of Physical Education teachers and academics.

The training session was carried out in three moments (Ribeiro and collaborators, 2017):

- Warm-up: stretching exercises (15 minutes)

- Main part: walking (20 minutes) and strength training (training A) and in the following session, strength training (training B), followed by 20 minutes of walking.

- Cool down: stretching activities, relaxation and body awareness work (10 minutes).

\section{Aerobic Training Protocol}

They performed 20 minutes of treadmill walking before strength training. For the determination of the intensity and knowledge of the cardiovascular condition, the values of the maximal exercise test were used, previously performed in the ergometry sector of the Cardiac Emergency Room of Pernambuco (PROCAPE), with Bruce's protocol in the technique.

A training target zone of $50 \%$ to $75 \%$ of the heart rate reserve (HRR) was used and the following formula was used for its use:

HRR $=[$ HRmax - HRrest $] \mathrm{x}$ intensity + HRrest (Marins, 1998) [24].

The heart beats were obtained and checked by palpating the radial artery, placing the index and middle fingers on the distal radius region in the left wrist, counted by the evaluator in ten seconds and multiplied by six [24].

\section{Strength Training Protocol}

It consisted of exercises against resistance performed with free weights (dumbbells and washers) and New Fit Equipment ${ }^{\circledR}$ machinery. For the load progression, the series system was used until momentary concentric failure [25]. The training protocols, organized for this study, followed the recommendations of the American Diabetes Association [26], involving large muscle groups and are described in tables 2 and 3. All exercises were prescribed with three sets of eight to sixteen repetitions and fortyfive second intervals between sets.

\begin{tabular}{|l|l|}
\hline \multicolumn{2}{|l|}{ TRAINING PROTOCOL A } \\
\hline Pectoralis Major & Pectoral Fly \\
\hline Deltoids & High rowing with dumbbell resistance \\
\hline Quadriceps Femoris & Leg extensors \\
\hline Biceps Brachii & $\begin{array}{l}\text { Alternating elbows flexion with dumbbell } \\
\text { resistance }\end{array}$ \\
\hline
\end{tabular}

Table 2: Training Protocol A

\begin{tabular}{|l|l|}
\hline \multicolumn{2}{|l|}{ TRAINING PROTOCOL B } \\
\hline Dorsals & Low pulley rowing \\
\hline Biceps femoris & Unilateral knee bending with shin splints resistance \\
\hline Triceps suralis & Bilateral plantar flexion \\
\hline Triceps brachii & Elbow extension on pulley \\
\hline
\end{tabular}

Table 3: Training Protocol B

\section{Maximal Oxygen Uptake Assessment}

To determine VO2max, the Rockport 1-Mile Walk Test [27] was performed, which consists of walking 1 mile (1,609 meters) as fast as possible.

The test was performed at the gymnasium of the Physical Education School of the University of Pernambuco. The route was measured and each participant was properly oriented as to how to perform the test, to avoid a rush or poor use of the proposed route.

The walking time was measured, recorded and immediately after the end of the course the heart rate (HR) was checked in the radial artery for 15 seconds, the value found was multiplied by four to obtain the result of HR in 1 minute [27].
The formula used to calculate VO2max, $\mathrm{ml} / \mathrm{kg} / \mathrm{min}$, specific for females, was as follows:

VO2max $(\mathrm{ml} / \mathrm{kg} / \mathrm{min})=132.853-(0.1692 \times$ WEIGHT $)-(0.3877 \mathrm{x}$ AGE $)$ $+(0)-(3.2649 \times$ TIME $)-(0.1565 \times$ HR $)$.

Weight was in kilograms; age was in years; time corresponded to the period of walking, taking the nearest hundredth of a minute $(13: 18=13.3$ $[18 / 60=0.3])$; and the heart rate used was the recovery heart rate, in beats per minute (bpm) [27].

\section{Ranking Table for Comparative Result}

The result of $\mathrm{VO} 2 \mathrm{max}$ obtained in the tests was compared with the classification table for physically active women, described by the American Heart Association (1972), as presented below. 


\begin{tabular}{|l|l|l|l|l|c|}
\hline Age group (years) & Very poor & Poor & Fair & Good & Excellent \\
\hline $20-29$ & $<24$ & $24-30$ & $31-37$ & $38-48$ & $\geq 49$ \\
\hline $30-39$ & $<20$ & $20-27$ & $28-33$ & $34-44$ & $\geq 45$ \\
\hline $40-49$ & $<17$ & $17-23$ & $24-30$ & $31-41$ & $\geq 42$ \\
\hline $50-59$ & $<15$ & $15-20$ & $21-27$ & $28-37$ & $\geq 38$ \\
\hline $60-69$ & $<13$ & $13-17$ & $18-23$ & $24-34$ & $\geq 35$ \\
\hline
\end{tabular}

Table 4: Maximum Oxygen Consumption for Physically Active Women (Vo2 Max - Ml/Kg.Min-1) By The American Heart Association - 1972 For Women

For the comparison with diabetic women, the VO2max was considered to be the minimum reference value for the "good" classification with an age range between 40 and 59 years, i.e., $28.0 \mathrm{ml} / \mathrm{kg}$. min.

\section{Statistical Analysis}

For data analysis the t test was applied for one sample, with significance $\mathrm{p} \leq 0.05$. To evaluate the correlation between the variables WEIGHT $\mathrm{x}$ Vo2max and AGE x Vo2max, a dispersion analysis was performed between the variables cited.

\section{Results}

After performing the walking test, it was observed that the mean VO2max of the diabetics evaluated was $16.8 \mathrm{ml} / \mathrm{kg} / \mathrm{min}$. This result was obtained by applying the Rockport 1-mile walk test, as previously described (American College of Sports Medicine [27].

\begin{tabular}{|l|l|l|}
\hline $\begin{array}{l}\text { Reference VO2max for trained non-diabetic women } \\
\text { (comparative)* }\end{array}$ & $28,0 \mathrm{ml} / \mathrm{Kg} / \mathrm{min}$ \\
\hline $\begin{array}{l}\text { VO2max for women with diabetes and chronic } \\
\text { complications (evaluated) } * *\end{array}$ & $16,8 \mathrm{ml} / \mathrm{Kg} / \mathrm{min}$ \\
\hline
\end{tabular}

Note: * Value used as reference for comparison of "good" VO2max rating for trained non-diabetic women, according to The American Heart Association- 1972. *** Mean value obtained in the Rockport 1 mile walk test for women with diabetes and chronic complications participating in the study.

\section{Table 5: Maximum Oxygen Consumption of The Participants}

According to Table 5, the participants of this study presented VO2max levels significantly lower than the recommended for the same age group of women without diabetes.

In order to evaluate the possible influence of age or weight on the results

A)

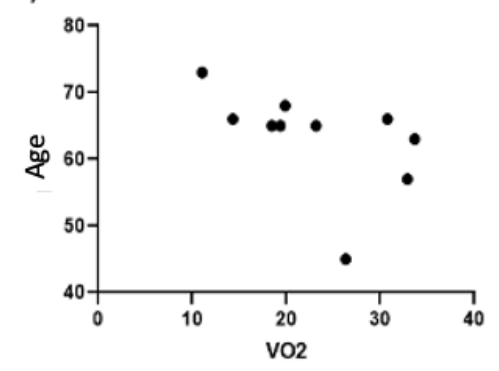

obtained, we also carried out an analysis of dispersion between the variables WEIGHT $x$ VO2max $(p=0.237)$ and AGE $x$ VO2max $(\mathrm{p}=0.252)$, graph $1 \mathrm{~A}$ and $\mathrm{B}$, respectively. It was observed that there was no correlation between these aforementioned variables, due to the fact that the points do not follow a positive or negative trend.

B)

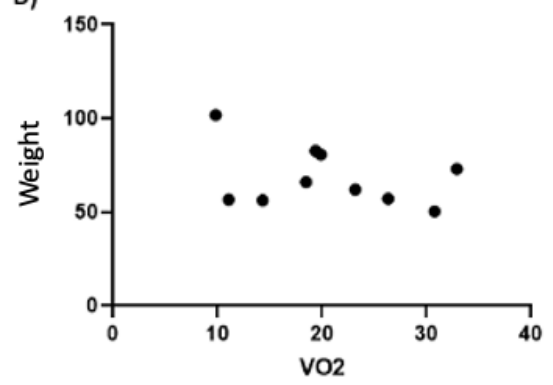

Graphic 1: correlation age vs. volumemax and weight vs. volumemax

Graphic 1. The dispersion analysis performed between the variables WEIGHT versus Vo2max and AGE versus Vo2max. A. Dispersion analysis between the variables age and VO2max showed no statistically significant difference $(p=0.252)$. B. Analysis of dispersion between the variables weight and VO2max showed no statistically significant difference $(p=0.237)$. Values represent mean $\pm S E M$. $(A, B) n=10$. $(P>0,05)$

\section{Discussion}

In this study, we showed that women with diabetes who have chronic complications, had the mean value of VO2max, obtained in the Rockport 1 mile walk test, of $16.8 \mathrm{ml} / \mathrm{kg} / \mathrm{min}$, a result significantly lower than that recommended by the American College of Sports Medicine (2006), for active women with good classification and age range between 40 and 59 years $(28.0 \mathrm{ml} / \mathrm{kg} / \mathrm{min})$.

According to the classification of the study conducted by Herdy and Caixeta (2016) [23], for active Brazilian women, the value found, is also below the classification considered regular, values between 24.89 - 29.54 $\mathrm{ml} / \mathrm{kg} / \mathrm{min}$, in addition, the results found, were still lower than the values adopted for sedentary women $(27.2 \pm 5.0 \mathrm{ml} / \mathrm{kg} / \mathrm{min})$.

This decrease in maximum oxygen consumption can be explained by the study of Colberg (2003) [28], which argues that individuals with DM2 present lower cardiorespiratory capacity measured by VO2max in relation to non-diabetic individuals, which may be related to several factors, including paternal overprotection, received during childhood, when they avoided physical activities for being diabetic.

Another factor that may contribute to the lower capacity of oxygen uptake by the muscles active during exercise would be a consequence of the syndrome itself, where the inefficiency or partial absence of insulin may 
interfere in the process of protein synthesis, leading to losses in the development of oxidative enzymes in the muscles of people with diabetes, a preponderant factor for the intracellular mechanisms of ATP resynthesis and exercise tolerance [28].

Metabolic problems, such as hyperglycemia and low lactic acid clearance during and after exercise and respiratory problems may be related to reduced anaerobic threshold, early fatigue and loss of performance in individuals with type 1 diabetes [29].

Pitocco and colleagues (2012) [30] point to the lung as one of the target organs affected by diabetes, due to prolonged exposure from high glucose levels.

Saler and collaborators (2009) [31] found a possible correlation between microalbuminuria and lung diffusion capacity in DM2, considering the possibility of being a risk factor contributing to the acceleration of respiratory aging in this population.

Kanya Kumari and collaborators (2011) [32] explain that individuals with DM2 have connective tissue changes in thickening of the alveolar epithelium and pulmonary capillary basal lamina leading to pulmonary microangiopathy, in addition to decreased lung elasticity due to nonenzymatic connective tissue glycosylation and may reduce lung capacity and possibly exercise tolerance.

In the study by Shah and colleagues (2013) [33], they confirm that DM is a systemic disease that also affects the lungs, causing changes due to connective tissue glycosylation, reduced elasticity and inflammatory changes, however, they disagree that glycemic levels and length of diabetes are a determining factor for ventilatory restriction.

Fibrous interstitial lung disease, which is the first step towards chronic, progressive, fibrotic lung disease is inflammatory in nature and, according to Richeldi and colleagues (2017) [34], can develop in a variety of ways. The same, due to the use of inhalant medications or in a secondary way to other diseases can cause changes in the connective tissue, besides suffering influence from environmental factors that may be exposed [35].

The aforementioned studies present additional losses to individuals with diabetes, showing that they have greater impairments related to their diagnosis, which leads us to believe that the chronic complications present in the sample evaluated, may be an important factor in the findings of this study. Studies have evaluated cardiorespiratory capacity associated with other alterations [35], the time of diabetes [30] and glycemic control [36]. Findings on pathophysiological changes seem to confirm that, in addition to other organs, the lung can also be affected by microvascular complications [37] and may come to interfere with cardiorespiratory function and exercise tolerance.

However, besides thinking of the lung as an affected target organ, justifying the low VO2max level, we must remember that the vitality of an individual also depends on the health of the skeletal muscle, which in turn depends on mitochondrial functions [38]. Em um estudo realizado com pessoas portadoras de DM2, observou-se que estes indivíduos apresentam danos mitocôndrias. Foi observado mitocôndrias com menores tamanhos, danificadas ou disfuncionais e essa disfunção mitocondrial do músculo esquelético foi associada à resistência à insulina e ao DM2 [39].

To rule out the hypothesis that the result of VO2max obtained could be influenced by variables other than the diagnosis of diabetes and the chronic complications presented by the volunteers, such as weight or age, we also investigated the possible correlation between weight and VO2max and age and VO2max of the evaluated women. We hypothesized that younger women or those with lower weight could present better results in the 1-mile test described in the methodology of this research.
However, the null correlation observed in the scatter plot shows that these variables were not preponderant for the VO2max results obtained. This result reinforces the influence of the diagnosis of diabetes and its complications on the VO2max results obtained.

However, there is still a lack of studies that compare the VO2max of women with active type 2 diabetes, without chronic complications, with that of women without diagnosis and of the same age group. Such an investigation may clarify whether the lower volume of oxygen taken up during exercise is really influenced by chronic complications of diabetes or whether the diagnosis itself already affects this outcome. Furthermore, investigating the influence of each type of chronic complication of diabetes on VO2max is also necessary, as we believe that some of the diagnoses may have a greater influence on the outcome investigated here.

\section{Conclusion}

The level of VO2max of type 2 diabetics diagnosed with chronic complications from diabetes who performed physical exercise was lower than the average recommended for people without diabetes, of the same age range, physically active and sedentary of the same age range. Diabetes and its chronic complications may have an influence on this result because degenerations, mainly at the pulmonary level and mitochondrial damage, caused by the disease itself, may decrease exercise tolerance. We suggest, therefore, that women with the profile of the participants in this study should be adequately evaluated, so that they can be submitted to an adequate periodization of physical exercises, aiming at better adaptation and greater adherence to physical exercise.

The results discussed in this study may explain the difficulty that health professionals have in making progressions in the intensity or volume of aerobic exercises and even the difficulty in adhering to physical exercise for this public.

However, it is necessary to emphasize the importance of evaluating different exercise protocols from those used in this study, in order to obtain more information regarding the adaptation of this population to exercise, especially with regard to improvements in VO2max values. In addition, the influence of chronic complications on the VO2max of women with diabetes without chronic complications needs to be better investigated.

\section{References}

1. Mafra T.C.A, Simões C.S.M, Vieira M.V.G.C, Lazzarotto L.R.B, Teixeira J.C.A, Miranda M.A.L, Vieira A. A, Ferreira A. A. M, Corrêa M. R, Bomfim I. P, Lacerda D. R, Pereira W. V. C. (2020). Obesity and Inflammatory Profile: Is Physical Exercise Ableto Reverse This Process? A Mini Review. Endocrinol Diabetes Metab J. Volume 4(2): 1-7.

2. Lyra R, Cavalcanti N, Santos R.D. (2019). Diabetes Mellitus: uma abordagem cardiovascular. São Paulo: Editora Clannad.

3. American Diabetes Association. (2020). Classification and Diagnosis of Diabetes. Diabetes Care. 43.

4. Tavares M, Ferreira Neta J, França J, Ribeiro J, Barbosa C, Silva V, Vancea d. (2016). Análise da percepção de diabéticos tipo 2 sobre a doença e o tratamento. R Epidemiol Control Infec. 6 (2); 85-91.

5. Vancea D.M.M, Vancea J.N, Pires M.I.F, Reis M.A, Moura R.B, Dib S.A. (2009). Efeito da frequência do exercício físico no controle glicêmico e composição corporal de diabéticos tipo 2. Arq Bras Cardiol. 92(1):23-30.

6. Moro A.R.P, Iop R.R, Silva F.C, Gutierres Filho P.J.B. (2012). Efeito do treinamento combinado e aeróbio no controle glicêmico no diabetes tipo 2. Fisioter Mov. 25(2): 399-409. 
7. American College of Sports Medicine. (2014). Diretrizes do ACSM para os testes de esforço e sua prescrição. 9 ed. Rio de Janeiro: Guanabara Koogan.

8. Cruz P.W.S, Buarque L.K, Lima G.N, Nobre I.G, Queiroz S.L, Ferreira M.N.L, Vancea D.M.M. (2012). Programa de exercício físico na redução do risco cardiovascular em diabéticos tipo 2. ConScientiae Saúde.; 11(3):413-419.

9. Komatsu W. R, Barros Neto T. L, Chacra A. R, \& Dib S. A. (2010). Aerobic Exercise Capacity and Pulmonary Function in Athletes with and Without Type 1 Diabetes. Diabetes Care. 33(12), 2555-2557.

10. Ribeiro J.N.S, Lima A.M.B, França J.A.L, Silva V.N.S.E, Cavalcanti C.B.S, Vancea, D.M.M. (2018). Doce Vida-programa de exercício físico supervisionado para diabéticos. Rev. Andal. Med. Deporte. Portugal. 11(3).

11. Cao L, Li X, Yan P, Wang X, Li M, Li R, Shui X, Liu X, Yang K. (2019). The effectiveness of aerobic exercise for hypertensive population: A systematic review and meta-analysis. J Clin Hypertens (Greenwich, Conn). 21(7), 868-876.

12. Wang Y, Xu D. (2017). Effects of aerobic exercise on lipids and lipoproteins. Lipids Health Dis. 16, 132.

13. Colberg S.R, Sigal, R.J, Yardley J.E, Riddell M.C, Dunstan D.W, Dempsey P.C, Horton E.S, Castorino K, Tate D.F. (2016). Physical Activity/Exercise and Diabetes: A Position Statement of the American Diabetes Association. Diabetes Care. 39(11): 2065-2079.

14. Albright A, Franz M, Hornsby G, Kriska A, Marrero D, Ullrich I, Verit L.S. (2000). American College of Sports Medicine position stand. Exercise and type 2 diabetes. Medicine and Science in Sports and Exercise. 32(7):1345-1360.

15. Picoli T.S, Figueiredo L.L, Patrizzi L.J. ( 2011). Sarcopenia e envelhecimento. Fisioter mov. 24(3).

16. Seco J, Abecia L. C, Echevarría E, Barbero I, Torres-Unda J, Rodriguez V, \& Calvo J. I. (2013). A long-term physical activity training program increases strength and flexibility and improves balance in older adults. Rehabilitation Nursing. 38(1); 37-47.

17. Dodds R, Sayer AA. (2014) Sarcopenia. Arq. Bras. Endocrinol. Metab. 58(5). 464-469.

18. Forster A, Lambley R, Hardy J, Young J, Smith J, Green J, Burns E. (2009). Rehabilitation for older people in long-term care. Cochrane Database of Systematic Reviews. 1; CD004294.

19. Sociedade Brasileira De Diabetes (SBD). (2019). Diretrizes da Sociedade Brasileira de Diabetes 2019-2020, São Paulo: Editora Clannad.

20. Cattuzzo M.A, Barros M.V.G. (2009). Atualização em Atividade Física e Saúde.

21. Nahas, M.V. (2013). Atividade Física, Saúde e Qualidade de Vida. 6 ed. Londrina: Miodiograf.

22. Pescatello L.S, Riebe D, Thompson P.D. (2014). ACSM's Guidelines for Exercise Testing and Prescription; Lippincott Williams \& Wilkins: Philadelphia, PA, USA.

23. Herdy A.H, Caixeta A. (2016). Classificação Brasileira de Aptidão Cardiorrespiratória Baseada no Consumo Máximo de Oxigênio. Arq. Bras. Cardiol. 106 (5), 389-395.
24. Marins J.C. (1998). Avaliação e prescrição de atividade física: guia prático. 2a edição. Rio de Janeiro; Shape.

25. Fleck S.J, Kraemer W.J. (2017). Fundamentos do treinamento de força muscular. $4^{\mathrm{a}}$ ed. Porto Alegre: Artmed.

26. American Diabetes Association. (2016). Physical Activity/Exercise and Diabetes: A Position Statement of the American Diabetes Association. Diabetes Care. 39. 2065-2079.

27. American College of Sports Medicine. (2006). Manual do ACSM para avaliação da aptidão física relacionada à saúde. 1 ed. Rio de Janeiro: Guanabara Koogan.

28. Colberg, S.R. (2003). Atividade Física e Diabetes. São Paulo: Manole.

29. Baraldi E, Monciotti C, Filippone M, San- tuz P, Magagnin G, Zanconato S, Zacch- ello F. (1992). Gas exchange during exercise in diabetic children. Pediatr Pulmonol. 13:155-160.

30. Pitocco D, Fuso L, Conte E.G. et al. (2012). The diabetic lung-a new target organ?. Rev. Diabet. Stud. 9(1):23-35.

31. Saler T, Cakmak G, Saglam Z.A, Ataoglu E, Erdem T Y, Yenigum $\mathrm{M}$. The assessment of pulmonary diffusing capacity in diabetes mellitus with regard to microalbuminuria. Intern Med. 48(22):1939-1943.

32. Kanya Kumari D.H, Natarajs M, Devarajh S. (2011). Correlation of duration of diabetes and pulmonary function tests in type 2 diabetes mellitus patients.Int J Biol Med Res. 2(4): 1168 -1170.

33. Shah S.H, Sonawane P, Nahar P, Vaidya S, Salvi S. (2013). Pulmonary function tests in type 2 diabetes mellitus and their association with glycemic control and duration of the disease. Lung India. 30(2): 108-112.

34. Richeldi L, Collard H.R, Jones M.G. (2017). Idiopathic pulmonary fibrosis. Lancet. 389(10082):1941-1952.

35. Lecube A, Ciudin A, Sampol G, Valladares S, Hernandez C, Simó R. Effect of glycemic control on nocturnal arterial oxygen saturation: a case-control study in type 2 diabetic patients. J Diabetes. 7(1):133-138.

36. Gutiérrez-Carrasquilla L, Sánchez e, Barbé f, Dalmases M, López-Cano C, Hernández M, Simó R, Lecube A. (2019). Effect of Glucose Improvement on Spirometric Maneuvers in Patients with Type 2 Diabetes: The Sweet Breath Study. Diabetes Care. 42 (4) 617-624.

37. Kopf S, Groener J.B, Kender Z, Fleming T, Brune M, Riedinger C, Volk N, Herpel E, Pesta D, Szendrödi J, Wielpütz M.O, Kauczor H. A, Kreuter M. (2018). Breathlessness and Restrictive Lung Disease: An Important Diabetes-Related Feature in Patients with Type 2 Diabetes. Respiration. 96(1):29-40.

38. Memme J.M, Erlich A.T, Phukan, G, Hood D.A. (2021). Exercise and mitochondrial health. J Physiol. 599(3):803-817.

39. Patti M.E, Butte A.J, Crunkhorn S, Cusi K, Berria R, Kashyap S, Miyazaki Y, Kohane I, Costello M, Saccone R, Landaker E.J, Goldfine A.B, Mun E, DeFronzo R, Finlayson J, Kahn C.R, Mandarino L.J. (2003). Coordinated reduction of genes of oxidative metabolism in humans with insulin resistance and diabetes: Potential role of PGC1 and NRF1. Proc Natl. Acad. Sci. U S A. 100(14):8466-8471. 